\title{
CHURG-STRAUSS SYNDROME AND ACTIVE CHRONIC HEPATITIS B VIRUS INFECTION: COINCIDENCE OR ASSOCIATION?
}

\author{
doi: 10.1590/S1807-59322010000300015
}

Diogo Souza Domiciano, Samuel Katsuyuki Shinjo, Maurício Levy-Neto

\section{INTRODUCTION}

The etiology of Churg-Strauss syndrome (CSS) is not well understood. Some case reports have suggested allergic desensitization, ${ }^{1}$ exposure to pigeons, ${ }^{2}$ cocaine use ${ }^{3}$ leukotriene receptor antagonist treatment ${ }^{4,5}$ and hepatitis vaccination $^{6,7}$ as putative etiological agents.

In the present study, we report the case of a patient who developed CSS after becoming infected with hepatitis B virus (HBV).

\section{CASE DESCRIPTION}

A 64-year-old Caucasian female who worked as a nurse technician was admitted to the Hospital das Clínicas da Faculdade de Medicina da Universidade de São Paulo after suffering from fatigue, malaise and fever for 30 days. She exhibited palpable purpuras in the legs and feet and reported having numbness in her feet fifteen days prior to the onset of her symptoms.

The patient had suffered from asthma since the age of 15 , for which she used inhaled corticosteroids. She had never used a leukotriene receptor antagonist or illicit drugs, such as cocaine, nor had she received a prophylactic HBV vaccination. However, six years earlier, she was accidentally punctured in the arm with a needle that was potentially contaminated with HBV.

A neurological examination revealed anesthesia in the left superficial peroneal and right plantar nerves, but no motor deficit or abnormalities in her reflexes. A

Department of Rheumatology, Hospital das Clinicas da Faculdade de Medicina da Universidade de São Paulo - São Paulo/SP, Brazil. Email: samuel.shinjo@gmail.com

Tel: 55113061.7492 blood chemistry analysis revealed that the patient had leukocytosis $\left(25,210 / \mathrm{mm}^{3}\right)$, with $68 \%$ of white blood cells being eosinophils, and she exhibited serum IgE levels of $829 \mathrm{mg} / \mathrm{dL}$. In addition, an examination of the patient's excrement gave a normal result. Her liver enzyme levels were slightly elevated. HBV serology revealed positivity for IgM anti-HBc and anti-HBe antibodies and HBsAg, the absence of anti-HBs antibodies and HBeAg and no HIV or hepatitis $\mathrm{C}$ infection. Parasitological tests were negative. Additional studies revealed that the patient was negative for anti-nuclear. The anti -rheumatoid factor was $211 \mathrm{U} / \mathrm{L}$ (NL: <25U/L) and lacked serum cryoglobulins. However, indirect immunofluorescence analysis indicated that she had low titers of p-ANCA (this result was not confirmed by testing for anti-MPO by ELISA). An echocardiogram revealed a moderate pericardial effusion with no other alterations. Spirometry showed mild obstructive airway disease. High-resolution computed tomography revealed a thickening of the bronchial walls and extensive areas of air capture, paranasal sinuses with diffuse mucosal thickening and polyps in the superior nasal meatus.

An electroneuromyography revealed mononeuritis multiplex in the lower extremities. Upon performing a skin biopsy, we found that the patient presented leukocytoclastic vasculitis with eosinophilic infiltration of the blood vessel walls, but there was no evidence of granuloma. An abdominal ultrasound indicated that her liver was heterogeneous, and a liver biopsy confirmed that she had active chronic HBV infection. While there were no signs of cirrhosis, she did present intense inflammatory eosinophilic infiltration of the periportal spaces (Figure 1) and focal fibrinoid necrosis of the vessels.

The patient had no proteinuria, no urinary sediment alterations and no creatinine elevation.

The patient was treated with $150 \mathrm{mg} /$ day of lamivudine 


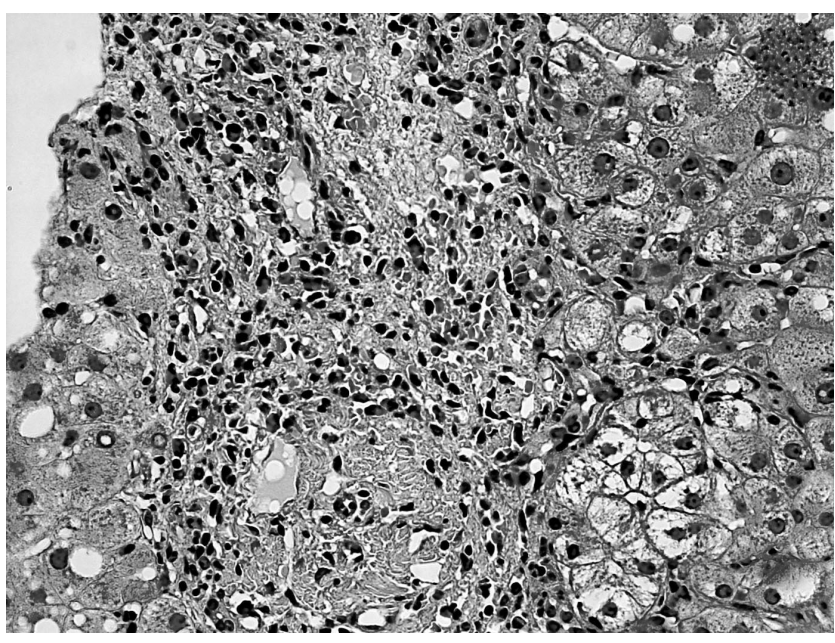

Figure 1 - Liver biopsy sections of active chronic hepatitis B infection without cirrhosis, but with intense inflammatory eosinophilic infiltration into the vessels and focal fibrinoid necrosis (hematoxylin and eosin, original magnification $40 \mathrm{X}$ )

and $1 \mathrm{mg} / \mathrm{kg} /$ day of prednisone, after which she achieved full recovery and regained normal liver function with no signs of viral replication. Therefore, cyclophosphamide and interferon treatment were not necessary.

Aside from the presence of vasculitis and a history of allergy, the patient had no infections and no history of drug use; therefore, it is unlikely that she suffered from hypereosinophilic syndrome. The patient was diagnosed with CSS according to the criteria of the American College of Rheumatology. ${ }^{8}$ We considered her positive response to therapy and full recovery from pericardial effusion as a manifestation of cardiac involvement secondary to CSS.

\section{DISCUSSION}

In the present work, we report a case of CSS that developed in a patient infected with HBV after she suffered an accidental puncture with a needle contaminated with HBV. Six years after this incident, she developed CSS, which may have been coincidental or associated with HBV infection.

To date, there has been only one case report of a patient who harbored a natural HBV infection and suffered from CSS that affected the colon. ${ }^{9}$ However, that report did not investigate whether the HBV infection triggered the onset of CSS. Another report described a case of CSS that was associated with both HBV and HIV infections. ${ }^{10}$

In conclusion, we have described a case of CSS that was associated with active chronic HBV infection. It is likely that chronic HBV infection triggered CSS in this patient.

\section{REFERENCES}

1. Guillevin L, Guittard TH, Bletry O, Godeau P, Rosenthal P. Systemic necrotizing angiitis with asthma: causes and precipitating factors in 43 cases. Lung. 1987;165:165-72.

2. Guillevin L, Amouroux J, Arbeille B, Boura R. Churg-Strauss angiitis: arguments favouring the responsibility of inhaled antigens. Chest. 1991;100:1472-3.

3. Orriols R, Muñoz X, Ferrer J, Huget P, Morell F. Cocaine-induced Churg-Strauss vasculitis. Eur Respir J. 1996;9:175-7.

4. Noth I, Strek ME, Leff AR. Churg-Strauss syndrome. Lancet. 2003;361:587-94.

5. Abril A, Calamia KT, Cohen MD. The Churg Strauss syndrome (allergic granulomatous angiitis): review and update. Semin Arthritis Rheum. 2003;33:106-14.

6. Vanoli M, Gambini D, Scorza R. A case of Churg-Strauss vasculitis after hepatitis B vaccination. Ann Rheum Dis. 1998;57:256-7.
7. Beretta L, Caronni M, Vanoli M, Scorza R. Churg-Strauss vasculitis with brain involvement following hepatitis B vaccination. Clin Exp Rheumatol. 2001;19:757.

8. Masi AT, Hunder GG, Lie JT, Michel BA, Bloch DA, Arend WP, et al. The American College of Rheumatology 1990 criteria for the classification of Churg-Strauss syndrome (allergic granulomatosis and angiitis). Arthritis Rheum. 1990;33:1094-100.

9. Kim YB, Choi SW, Park IS, Han JY, Hur YS, Chu YC. Churg-Strauss syndrome with perforating ulcers of the colon. J Korean Med Sci. 2000;15:585-8.

10. Cooper LM, Patterson JAK. Allergic granulomatosis and angiitis of Churg-Strauss. Case report in a patient with antibodies to human immunodeficiency virus and hepatitis B virus. Int J Dermatol. 1989;28:597-9. 